Nonlinear Processes in Geophysics (2003) 10: 441-452

Nonlinear Processes

in Geophysics

(c) European Geosciences Union 2003

\title{
A quasi-analytical ice-sheet model for climate studies
}

\author{
J. Oerlemans \\ Institute for Marine and Atmospheric Research, Utrecht University Princetonplein 5, 3584 CC UTRECHT, The Netherlands
}

Received: 16 January 2003 - Revised: 31 March 2003 - Accepted: 1 April 2003

\begin{abstract}
A simple quasi-analytical model is developed to study the response of ice-sheets to climate change. The model is axi-symmetrical and rests on a bed with a constant slope. The mechanics are highly parameterised. The climatic conditions are represented by the altitude of the runoff line. Above the runoff line the accumulation rate is constant (but may depend on, for instance, the ice-sheet size), below the runoff line the balance gradient is constant. The ice-sheet may extend into the sea and can respond to changes in sea level. At the grounding line the ice velocity is assumed to be proportional to the water depth. For this set-up an explicit expression for the total mass budget of the ice-sheet is derived.

To illustrate the properties and possibilities of the model, equilibrium states are analysed and the response to periodic forcing is studied as well. The coupling of mass balance and surface elevation of the ice-sheet leads to nonlinear behaviour and branching of the equilibrium solutions. The qualitative behaviour of the system is that of the cusp catastrophe. Nonlinear effects are more pronounced when the slope of the bed is smaller.

A case is discussed in which two ice-sheets are coupled by making the altitude of the runoff line dependent on the total area of the two ice-sheets. On two continents, having a slightly different glaciation threshold, periodic forcing of the altitude of the runoff line is imposed. It is shown that in such a situation variations on a long time scale (two to three times the period of the forcing) are introduced.

Finally the model is forced by the GISP $\delta^{18} \mathrm{O}$ record for the last 120000 years. For an appropriate choice of parameters the model simulates well the waxing and waning of the Laurentide, Fennoscandian and Barentsz ice-sheets.
\end{abstract}

\section{Introduction}

In the pioneering work of Weertman $(1961,1976)$ on the response of continental ice-sheets to climate forcing, a sim-

Correspondence to: J. Oerlemans (j.oerlemans@phys.uu.nl) ple analytical model was used to express the mass budget as a function of the height of the equilibrium line. Using a parabolic cross section in north-south direction and fixing the northern tip of the model ice-sheet at a certain latitude (the shoreline of the Arctic Ocean), he showed that multiple steady states were possible for a range of values of the equilibrium-line altitude. To arrive at a tractable equation (a second-order equation for the ice-sheet size), Weertman had to assume that accumulation and ablation rates are constant. By forcing his model with the Milankovitch insolation variations, Weertman showed that some of the features in the icevolume record from deep-sea sediments were reproduced.

Next one-dimensional (north-south spatial resolution) numerical ice-sheet models were developed to cope with some of the drawbacks in Weertman's theory (e.g. Oerlemans, 1980, 1982; Pollard, 1982; Deblonde and Peltier, 1991). Notably, it was now possible to let the ablation rate increase with decreasing altitude, and to include the role of high grounds in the process of glacial inception. The delay in the bed response to a varying ice load could also be treated more explicitly. It appeared that such models were more successful in generating power at the longer time scales (including the $100 \mathrm{kyr}$ peak that dominates the power spectra of oxygen isotope records from deep-sea sediments).

With increasing computing power the state-of-the-art now is to run 2- or 3-dimensional ice-sheet models with considerable spatial resolution coupled to a climate model of intermediate complexity, or asynchronously coupled to a comprehensive climate model (Marsiat, 1994; Tarasov and Peltier, 1997; Bintanja et al., 2002). Such an approach offers great possibilities, in particular when the goal is to correlate model output with proxy records that are affected by regional climate processes.

However, it is always useful to develop a hierarchy of models, and to see what features are so robust that they appear in simple as well as in comprehensive models. The purpose of this paper is to develop an ice-sheet model that is simple enough to allow a straightforward and adequate analysis of the dynamic properties, but on the other hand contains 
a description of the mass balance field that is realistic enough to perform meaningfull climate-change experiments.

There are a number of major differences with the model originally developed by Weertman. First of all, the ablation rate is not constant but increases with decreasing surface height, which is certainly more realistic. Secondly, the ice-sheet is allowed to enter the ocean and form an ice shelf or calving ice front. Although ice shelves are not modelled explicitly, the flux of ice across the grounding line enters the mass budget equation and thus effects the evolution of the ice-sheet. In fact, the model is able to generate a large icesheet in a situation where a small island is surrounded by a shallow sea (a common situation on the Eurasian Arctic continental shelf). Thirdly, the model is axi-symmetric, in contrast to the original Weertman model which is 1-dimensional (noth-south) with the tip of the ice-sheet fixed at the southern shore of the Arctic Ocean. Arguments for using an axisymmetric geometry will be given in Sect. 2.

The formulation developed in this paper can be applied to the major Pleistocene ice-sheets, and the resulting models can be coupled by parameterisations of climatic teleconnections (e.g. climatic conditions in Scandinavia are more favourable for ice-sheet growth when there is an ice-sheet in North America).

Because the model is basically 0-dimensional, with the size of the ice-sheet as the only state variable, it is computationally very efficient. One of the possible applications therefore is inverse modelling with Monte Carlo techniques, in which geological information on the extent of ice-sheets and/or sea level is used to reconstruct a climate change scenario that fits best.

\section{Geometry}

In this paper we consider axi-symmetric ice-sheets on beds that slope linearly downwards from the centre. The main reason for this is that ice-sheets will always start to form in the higher places, simple because the specific mass balance increases with height. In the course of time it has become clear that the classical picture of Northern Hemisphere ice-sheets that originate at the Arctic Ocean and then grow southwards is not a better representation of reality than axi-symmetric ice-sheets that start at high grounds and then expand in all directions. Also, the purpose of this paper is to develop a model that can also be applied to small ice caps like those on Iceland, or on the Arctic islands. Therefore an axi-symmetric geometry is a natural choice.

One of the basic assumptions in this theory is that the surface height of an ice-sheet varies with the square root of the distance to the centre. This is not an arbitrary choice, but inspired by the fact that, if ice were a perfectly plastic material and the original bed horizontal, the surface height of an ice-sheet model is parabolic (e.g. Weertman, 1976):

$h(r)=\left(\mu_{0}(R-r)\right)^{1 / 2}$
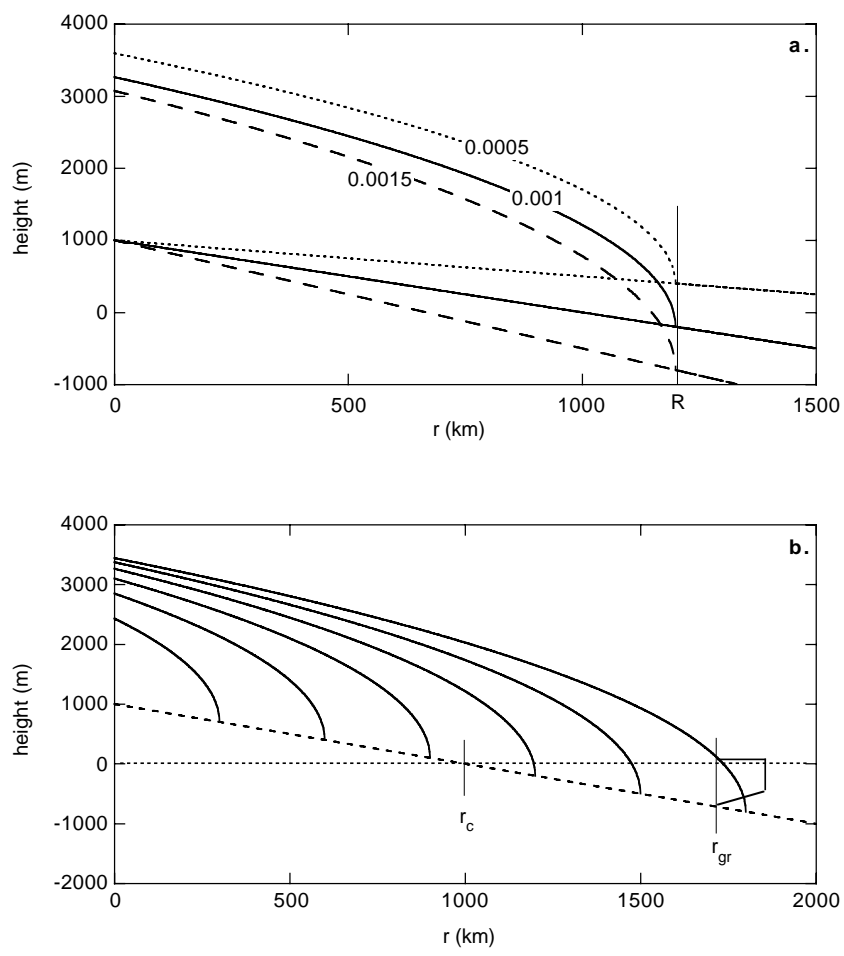

Fig. 1. (a) Geometry of the model ice-sheet for three values of the slope of the undisturbed bed (labels). Note that the actual bed, which is depressed by the ice load, is not shown. (b) Geometry for different values of the ice-sheet radius. At $r=r_{c}$ the terminus of the ice-sheet enters the sea. The undisturbed bed slope is 0.001 . Other parameter values are: $d_{0}=1000 \mathrm{~m}, \mu_{0}=8 \mathrm{~m}^{1 / 2}, c=2 \cdot 10^{6} \mathrm{~m}^{1 / 2}$

Here $r$ is the horizontal coordinate $(r=0$ at the centre of the ice-sheet), $h$ is the surface elevation, $\mu_{0}$ is the profile parameter, and $R$ is the radius of the ice-sheet. The plasticity solution is for a bed that is horizontal originally (i.e. if there is no ice load), and then depressed to maintain glacio-isostatic equilibrium. Note that in this case both the surface height $h(r)$ and the ice thickness $H(r)$ vary with the square root of $r$.

However, in the present study we assume that the undisturbed bed is not horizontal but slopes linearly downwards away from the ice-sheet centre (Fig. 1):

$d(r)=d_{0}-s r$

The undisturbed height of the bed at the centre is denoted by $d_{0}$, the bed slope by $s$. We assume that the shape of the surface profile is not affected by $s$. However, for a given value of $d_{0}$, the mean surface elevation will decrease for increasing $s$. This effect can be taken into account by the following formulation of the ice-sheet profile:

$h(r)=d_{0}-s R+(\mu(R-r))^{1 / 2}$,

where

$\mu=\mu_{0}+c s^{2}$. 
This parameterisation of the global effect of the bed slope is based on numerical experimentation with a plane-shear glacier model, in which the ice thickness and bed depression are calculated explicitly as a function of $r$. In the Appendix a more detailed discussion on this point is presented. For sufficiently small bed slopes $(s<0.005)$ it appears that adequate parameter values are $\mu_{0}=12 \mathrm{~m}^{1 / 2}$ and $c=2 \cdot 10^{6} \mathrm{~m}^{1 / 2}$.

In Fig. 1a ice-sheet profiles are shown for three values of the bed slope. For all cases discussed in this paper we have $0.0005 \leq s \leq 0.0015$. Note that the real bed, which is depressed to maintain isostatic equilibrium, is not shown. The relation between $R$ and the volume of the ice-sheet is discussed later.

We also want to apply the model in cases where the icesheet edge pushes into the sea to form a calving ice-sheet. For this purpose we use the same profile with the tip of the parabola ending on the sea floor. The position of the grounding line, denoted by $r_{g r}$, is where the ice is just floating, i.e.

$\rho_{w}\left(s r_{g r}-d_{0}\right)=\rho_{i}\left(s r_{g r}-d_{0}+h_{g r}\right)$,

where $h_{g r}$ is the height of the ice surface at the grounding line. Water density is denoted by $\rho_{w}$, ice density by $\rho_{i}$. Equations (3) and (5) can be combined to give

$$
\begin{aligned}
d_{0}-s R+\left(\mu\left(R-r_{g r}\right)\right)^{1 / 2} & =h_{g r} \\
& =\frac{\rho_{w}-\rho_{i}}{\rho_{i}}\left(s r_{g r}-d_{0}\right)
\end{aligned}
$$

This is a quadratic equation for $r_{g r}$ which can easily be solved. However, only a very small error is made by setting the right-hand side of Eq. (6) to zero (i.e. positioning the grounding line at the intersection of the parabola with sea-level, see Fig. 1b). This yields a particularly simple expression for $r_{g r}$ :

$r_{g r}=R-\mu^{-1}\left(s R-d_{0}\right)^{2}$

The approach taken here implies that for a deeper grounding line a larger part of the standard profile is cut off. This has the implicit advantage that the surface slope at the grounding line is smaller when the ice thickness at the grounding line is larger. An inspection of the surface and bed topography of the Antarctic ice-sheet makes clear that this is observed in reality, although there is no claim here that anything of the related physical processes is included in the model. A set of ice-sheet profiles for a bed slope of 0.001 is shown in Fig. 1b. An ice shelf has been depicted for the largest ice-sheet, but the shelf itself does not play a role in the dynamics.

In a later stage we want to compute the evolution of the ice-sheet from:

$\frac{d V_{t o t}}{d t}=B_{t o t}$

Here $V_{t o t}$ is the total ice volume, $t$ is time and $B_{t o t}$ is the total mass budget of the ice-sheet. To calculate the volume we first ignore the response of the bed to the ice load. In the case of a continental ice-sheet $\left(R<r_{c}\right)$ we find

$V=2 \pi \int_{0}^{R} H(r) r d r=\frac{8 \pi \mu^{1 / 2}}{15} R^{5 / 2}-\frac{1}{3} \pi s R^{3}$

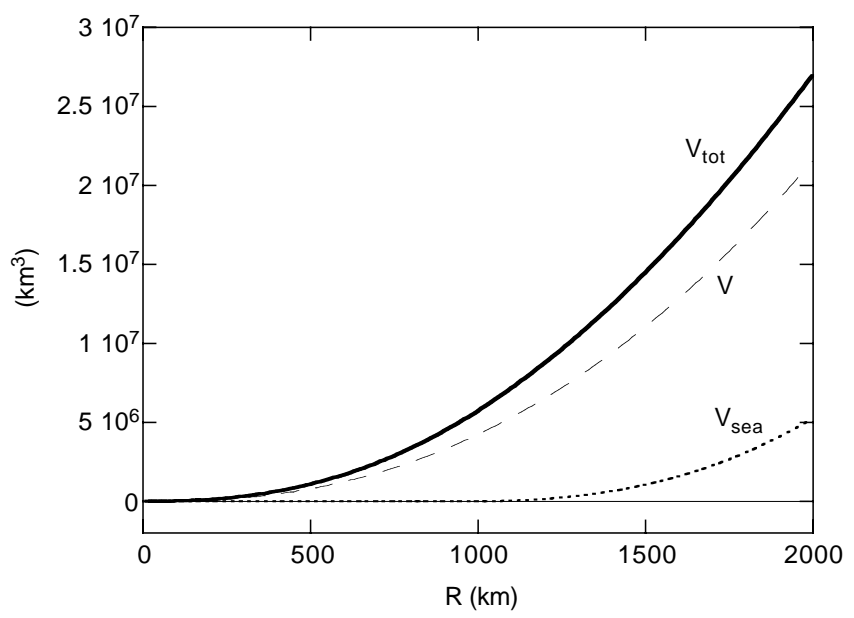

Fig. 2. Total ice-sheet volume $\left(V_{t o t}\right)$ as a function of the ice-sheet radius $R$. Volume in the case of no bed response $(V)$ and the amount of displaced sea water $\left(V_{\text {sea }}\right)$ are also shown. Model parameters as for Fig. 1.

A further algebraic exercise, not reproduced here, shows that this expression is also a good approximation for the case of a marine ice-sheet. The reason for this is that the tip of the parabola, describing the basic ice-sheet profile, and the position of the grounding line are always very close.

Next we have to deal with the response of the bed to the ice load. We assume that the system is always in isostatic balance, which implies

$\rho_{i} V-\rho_{w} V_{\text {sea }}+\rho_{i} V^{*}=\rho_{m} V^{*}$

Here $V$ is the volume as defined by Eq. (9), $V_{\text {sea }}$ is the volume of the sea water replaced by ice, and $V^{*}$ the volume of the mantle material replaced by ice. The density of the mantle is denoted by $\rho_{m}$. From Eq. (10) we find that the total volume is given by

$$
\begin{aligned}
V_{\text {tot }} & =V+\frac{\rho_{i}}{\rho_{m}-\rho_{i}} V-\frac{\rho_{w}}{\rho_{m}-\rho_{i}} V_{\text {sea }} \\
& =\left(1+\epsilon_{1}\right) V+\epsilon_{2} V_{\text {sea }},
\end{aligned}
$$

where

$\epsilon_{1}=\frac{\rho_{i}}{\rho_{m}-\rho_{i}}, \quad \epsilon_{2}=\frac{\rho_{w}}{\rho_{m}-\rho_{i}}$

and $V_{\text {sea }}$ is approximated as:

$$
\begin{aligned}
V_{\text {sea }} & =2 \pi \int_{r_{c}}^{R}\left(s r-d_{0}\right) r d r \\
& =\pi\left(\frac{2}{3} s\left(R^{3}-r_{c}^{3}\right)-d_{0}\left(R^{2}-r_{c}^{2}\right)\right)
\end{aligned}
$$

Figure 2 shows how these expressions work out. For a given slope, $V, V_{\text {sea }}$ and $V_{\text {tot }}$ are shown as a function of $R$. As expected, the isostatic depression of the bed has a significant effect on the total ice volume. The magnitude of $V_{\text {sea }}$ 
depends very much on the height of the undisturbed bed with respect to sea level, of course.

We are now able to relate $d R / d t$ to $d V_{\text {tot }} / d t$. It follows that for a calving ice-sheet

$$
\begin{gathered}
\frac{d V_{t o t}}{d t}=\left(\pi\left(1+\epsilon_{1}\right)\left[\frac{4}{3} \mu^{1 / 2} R^{3 / 2}-s R^{2}\right]\right. \\
\left.+2 \epsilon_{2}\left[\pi s R^{2}-d_{0} R\right]\right) \frac{d R}{d t}=B_{t o t}
\end{gathered}
$$

If the ice-sheet is not calving the second term within \{\} should be set to zero.

This completes the description of the geometric part of the model. For any given forcing $B_{t o t}$, the evolution of the icesheet can be calculated from Eq. (13). However, it is the dependence of $B_{t o t}$ on the shape of the ice-sheet which creates interesting nonlinear behaviour. In the next section the mass-balance field is described and an analytical expression for $B_{t o t}$ is derived.

\section{Mass budget}

To formulate the mass balance we use the concept of the runoff line. Its altitude is denoted by $h_{R}$. Above the runoff line the specific balance $B$ is constant, below the runoff line the balance gradient (with altitude) is constant. This is of course a simplification of reality. Normally, above the runoff line there is still loss of mass by sublimation. Also, the accumulation is not constant but shows considerable variations. On the Greenland ice-sheet for instance, the accumulation rate in the southeastern part of the ice-sheet is typically five times as large as in the dry northern parts. However, in the model formulation developed further on this is not of great importance, because it is the total accumulation that appears in the final expression for the mass budget.

Therefore we proceed with

$$
\begin{array}{lll}
B=A & \text { for } & h \geq h_{R} \\
B=A-\beta\left(h_{R}-h\right) & \text { for } & h<h_{R}
\end{array}
$$

Here $\beta$ is the balance gradient with respect to altitude. We note that the altitude of the runoff line can be related easily to the more commonly used altitude of the equilibrium line $h_{E}$ :

$h_{E}=h_{R}-A / \beta$

However, in this section using the runoff line is more convenient because it leads to a somewhat simpler expression for the total surface mass budget.

In Fig. 3 some observed balance profiles are shown (Haakensen, 1995; Haeberli et al., 1998). They have been chosen in such a way that the difference for maritime and continental glaciers shows up clearly. The curve for the Greenland ice-sheet is derived from a simulation with a high-resolution mass balance model (Van de Wal and Oerlemans, 1994). Clearly, the balance gradient varies widely. According to Fig. 3 we may use as characteristic values $A=1 \mathrm{~m}$ ice/yr and

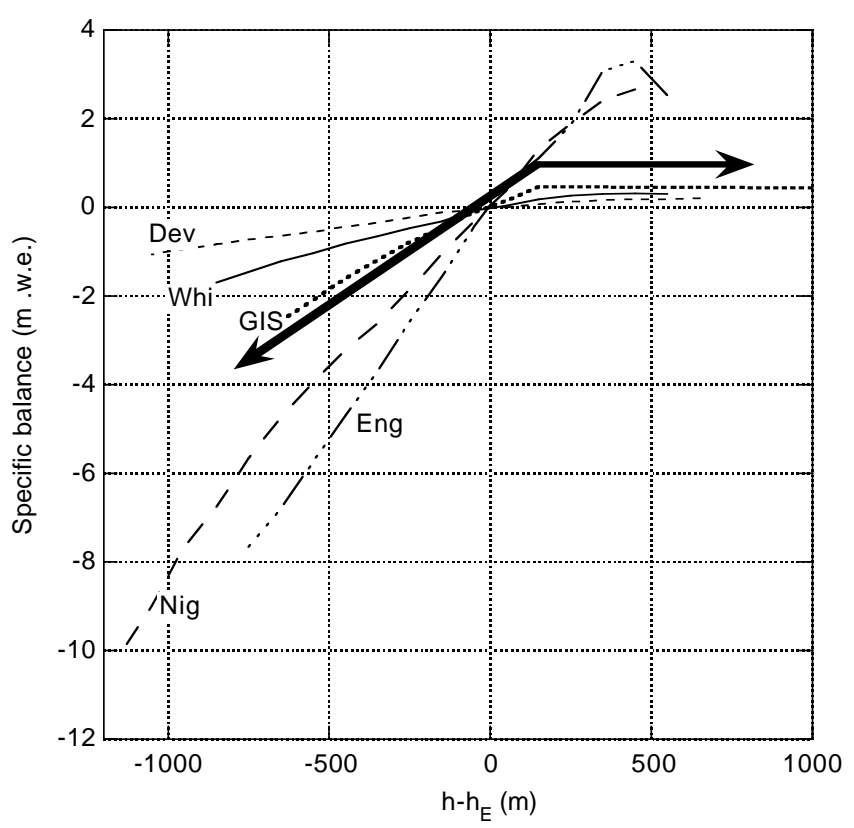

Fig. 3. Specific balance for a selection of glaciers. Legend: GIS = Greenland ice-sheet, Dev = Devon ice cap (Canadian Arctic), Whi $=$ White Glacier (Canadian Arctic), Nig = Nigardsbreen (southern Norway), Eng = Engabreen (central Norway). The solid line shows the form of the parameterisation used in the model.

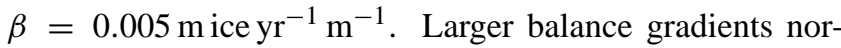
mally come with higher accumulation rates. Although we do not invoke such a relation here, it can easily be incorporated when the model is used for climate-change experiments.

For a continental ice-sheet $\left(R<r_{c}\right)$ the mass budget is found to be:

$$
\begin{aligned}
B_{t o t} & =\int_{0}^{2 \pi} \int_{0}^{R} B r d r d \phi \\
& =\pi A R^{2}-\pi \beta\left(h_{R}-d_{0}+s R\right)\left(R^{2}-r_{R}^{2}\right) \\
& +\frac{4 \pi \beta \mu^{1 / 2}}{5}\left(R-r_{R}\right)^{5 / 2}-\frac{4 \pi \beta \mu^{1 / 2}}{3} R\left(R-r_{R}\right)^{3 / 2}
\end{aligned}
$$

Here $r_{R}$ is the location where the runoff line intersects the ice-sheet surface. It is given by

$r_{R}=R-\mu^{-1}\left(h_{R}-d_{0}+s R\right)^{2}$

For a marine ice-sheet $\left(R>r_{c}\right)$, the integration is ex- 
tended until $r_{g r}$ only, so:

$$
\begin{aligned}
B_{t o t}= & \int_{0}^{2 \pi} \int_{0}^{r_{g r}} B r d r d \phi \\
= & \pi A r_{g r}^{2}-\pi \beta\left(h_{R}-d_{0}+s R\right)\left(r_{g r}^{2}-r_{R}^{2}\right) \\
& +\frac{4 \pi \beta \mu^{1 / 2}}{5}\left(\left(R-r_{R}\right)^{5 / 2}-\left(R-r_{g r}\right)^{5 / 2}\right) \\
& +\frac{4 \pi \beta \mu^{1 / 2}}{3}\left(R\left(R-r_{R}\right)^{3 / 2}-R\left(R-r_{g r}\right)^{3 / 2}\right)
\end{aligned}
$$

In the case of a marine ice-sheet there will also be loss of ice through discharge into the ocean. As in Oerlemans (2002), we only consider the volume flux across the grounding line and assume that the azimuthally-averaged ice velocity at the grounding line is proportional to the water depth. This admittedly is a very schematic approach. In reality marine icesheets have stagnant parts and ice streams that are active for some time. Mass discharge by ice streams is irregular and not always directly related to climatic forcing. Nevertheless, it seems reasonable to parameterise the integrated effect of ice streams and more slowly moving lobes by an expression that relates azimuthally-averaged ice velocity to azimuthallyaveraged water depth at the grounding line.

The total flux across the grounding line equals the ice velocity times the ice thickness at the grounding line, which leads to

$$
F_{g r}=2 \pi R f \delta\left(s r_{g r}-d_{0}+\eta\right)^{2}
$$

Here $f$ is a bulk flow parameter for ice at the grounding line. Its order of magnitude is $1 \mathrm{yr}^{-1}$ (Oerlemans, 2002). Changes in sea-level affect the depth at the grounding line and therefore the ice discharge. Therefore, a quantity $\eta$ is included, which is defined as eustatic sea level with respect to a datum state $(\eta=0)$. In principle it is possible to include the feedback of ice volume on sea level, but it should be realised that the relation between global ice volume and sea level is a complicated one with many local and regional effects (e.g. Tushingham and Peltier, 1991; Milne et al., 2002). In the applications of the ice-sheet model discussed further on, the height of the runoff line is defined with respect to the sealevel datum state $(\eta=0)$.

Equilibrium states of the model ice-sheet can now be calculated by setting $B_{t o t}=0$ for a continental ice-sheet, or by setting $B_{t o t}-F_{g r}=0$ for a marine ice-sheet. Because the resulting equation is of a high order in $R$, this cannot be done analytically. However, it is easy to obtain the equilibrium values of $R$ by a numerical technique (e.g. Newton-Raphson) or by integration of the time-dependent equation.

\section{Equilibrium states}

In this section we study equilibrium states. These states were calculated by integrating Eq. (13). Because hysteresis is a frequently occurring dynamic feature in ice-sheet models with height - mass balance feedback (Weertman, 1961;
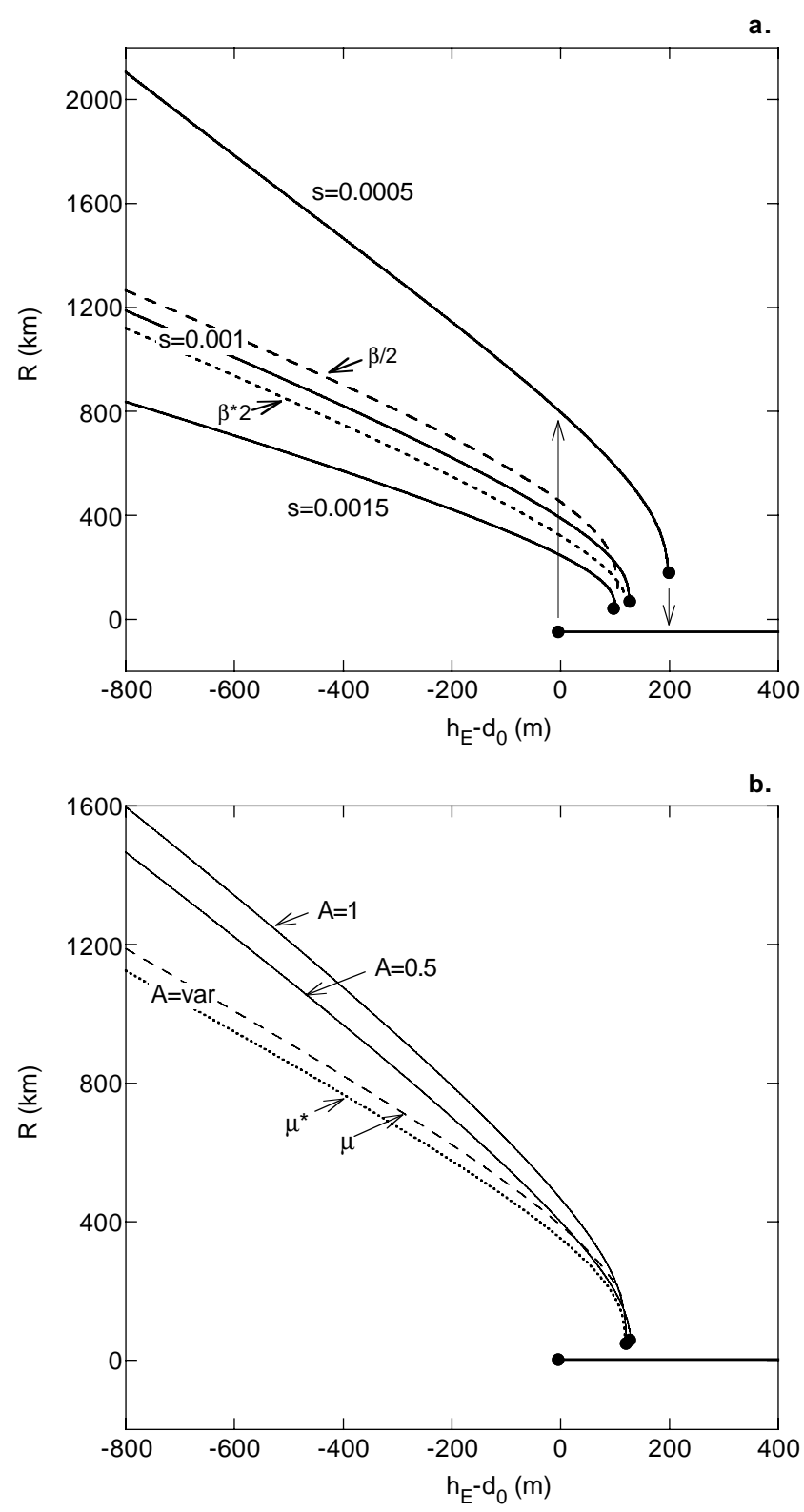

Fig. 4. (a) Stable equilibrium states of the model ice-sheet for three different values of the bed slope $s$. Bifurcation points are indicated by dots. The dotted lines refer to calculations (for $s=0.001$ ) in which the balance gradient $\beta$ was halved or doubled. (b) Stable equilibrium states for different values of the accumulation rate $A$ (in $\mathrm{m}$ of ice per year). The dotted line $\left(\mu^{*}\right)$ refers to a calculation in which the profile parameter depends on the accumulation rate.

Oerlemans, 1981), integrations should be done with at least two initial conditions: no ice-sheet and a large ice-sheet. We first consider continental ice-sheets. In this case the model formulation is invariant for the reference level for altitude, so results are presented as a function of $h_{E}-d_{0}$, i.e. the height of the equilibrium line with respect to the highest point of the bed (as defined for the ice-free case).

Figure 4 shows equilibrium states for different model pa- 
rameters. It is clear that for $h_{E}>d_{0}, R=0$ always represents an equilibrium state. Then there is a range of values for $h_{E}$ for which two stabe equilibrium states are possible (one of which is $R=0$ ). The bifurcation points are indicated by dots. In the following discussion we denote the equilibriumline altitude where the bifurcation point is found by $h_{\text {crit }}$. Curves are plotted for different values of $s$, showing that the value of $h_{c r i t}-d_{0}$ increases in a nonlinear way with decreasing slope of the bed. In fact, for $s \rightarrow \infty$ a stable ice-sheet is not possible: it either grows to infinity or shrinks to zero. The unstable equilibrium states are not shown. The unstable branches simply run from the bifurcation point to the origin of the plot $R=0, h_{E}=d_{0}$. The dynamic properties of the model ice-sheet can also be described in terms of a hysteresis effect. For $s=0.0005$ this is indicated by arrows.

The qualitative behaviour of the model has the characteristics of the elementary cusp catastrophe (Thom, 1975). Although the equation for $R$ is of fifth order, the quadratic term dominates and generates a fold catastrophe. However, because an additional constraint is imposed $(R \geq 0), R=0$ represents a stable equilibrium state for part of the parameter space. This then results in a structure that is very similar to the cusp catastrophe.

The solution diagram is qualitatively similar to the one described by Weertman $(1961,1976)$ for a one-dimensional (north-south) Northern Hemisphere ice-sheet on a horizontal bed, with an equilibrium line that slopes upward in southerly direction. However, to obtain an equation for the ice-sheet size that could be solved analytically, Weertman had to assume that there is an accumulation area with a constant accumulation rate and an ablation area with a constant ablation rate. This delivers a quadratic equation for the ice-sheet size. Although Weertman's analysis was of an admirable directness and simplicity, it is a fact that the assumption of a constant ablation rate is rather unrealistic. This assumption leads to ice-sheets that are more sensitive to changes in $h_{E}$, because a smaller/larger ice-sheet implies a relatively small decreas/increase in the total ablation. Nevertheless, the qualitative behaviour of the Weertman model and the present model is similar.

The dashed curves in Fig. 4a reveal the sensitivity of the equilibrium states to changes in the balance gradient $\beta$ (shown only for $s=0.001$ ). Doubling or halving the value of $\beta$ has some effect, but the differences are not very large. Figure $4 \mathrm{~b}$ shows how the equilibrium states depend on the the accumulation rate $A$ (for $s=0.001$ ). Again the differences are significant but not very large.

When ice-sheets become large it is likely that the mean accumulation rate will become smaller. It is therefore interesting to parameterise this effect and calculate how the solution curve changes. A possible formulation is:

$A=A_{0} \exp \left(-R / C_{R}\right)$

This expression implies that $A$ decreases exponentionally with the ice-sheet size with an $e$-folding spatial scale of $C_{R}$. The curve shown in Fig. $4 \mathrm{~b}$ (' $A=$ variable') is for $A=1.0 \mathrm{~m}$ ice $/ \mathrm{yr}$ and $C_{R}=500 \mathrm{~km}$. As expected, it is more difficult now for the ice-sheet to become big. The dependence of $R$ on $h_{E}$ weakens.

For the simple 'Vialov solution' (an ice-sheet of a given size on a flat bed with a constant accumulation rate, and deforming according to Glen's flow law for simple shear; Vialov, 1958), the mean thickness varies with the $1 / 8$ power of the accumulation rate (e.g. Oerlemans and Van der Veen, 1984; Van der Veen, 1999). Although this dependence of the ice thickness to the mass balance field (for given ice-sheet size!) is absent in the perfectly-plastic model, the potential importance of this effect can be studied by modifying the profile parameter according to

$\mu^{*}=\mu\left(A / A_{r e f}\right)^{1 / 8}$.

For the case with variable $A$ this then produces the dotted curve in Fig. 4b. $A_{\text {ref }}$ has been set to $1 \mathrm{~m}$ ice/yr. It is clear that the effect is not very large.

In the present analysis the runoff line is horizontal. However, including the effect of a runoff line that slopes upward or downward from the ice-sheet centre is straightforward. We can write

$h_{R}=h_{R, 0}+\gamma r$

where $\gamma$ is the tilt of the runoff line and $h_{R, 0}$ is the height of the runoff line at $r=0$. The value of $r$ at which the runoff line intersects the ice surface $\left(r_{R}\right)$ is now found from

$d_{0}-s R+\left(\mu\left(R-r_{R}\right)\right)^{1 / 2}=h_{R, 0}+\gamma r_{R}$

This expression replaces Eq. (17). Equation (23) is a quadratic equation for $r_{R}$ and is easily included in the calculations. It turns out that the resulting equilibrium solutions are very similar to those for a horizontal runoff line, if $s$ is replaced by $s+\gamma$. This implies that an equilibrium line that slopes upwards with the distance to the ice-sheet centre will make an ice-sheet less sensitive to climate change.

For a calving ice-sheet the solution diagram looks different, as illustrated by Fig. 5. Results can no longer be formulated in dependence of $h_{E}-d_{0}$, because $d_{0}$ determines for which value of $R$ ice is lost to the ocean (for a given slope of the bed). The introduction of calving makes the icesheet less sensitive to changes in the equilibrium-line altitude. The lower panel in Fig. 5 shows how the components of the mass budget vary with $h_{E}$. When $h_{E}$ is somewhat below sea level the runoff becomes zero (in fact, this happens when the runoff line is at sea level; then the ice-sheet radius becomes independent of $h_{E}$ ).

Altogether, from this survey of equilibrium states it can be concluded that the parameter sensitivity is dominated by the description of the mass balance field and the slope of the bed. Although one cannot state that mechanical effects are insignificant, the results obtained so far in this analysis motivate a further use of the simple ice-sheet model in cases where the environmental forcing varies strongly in time. 

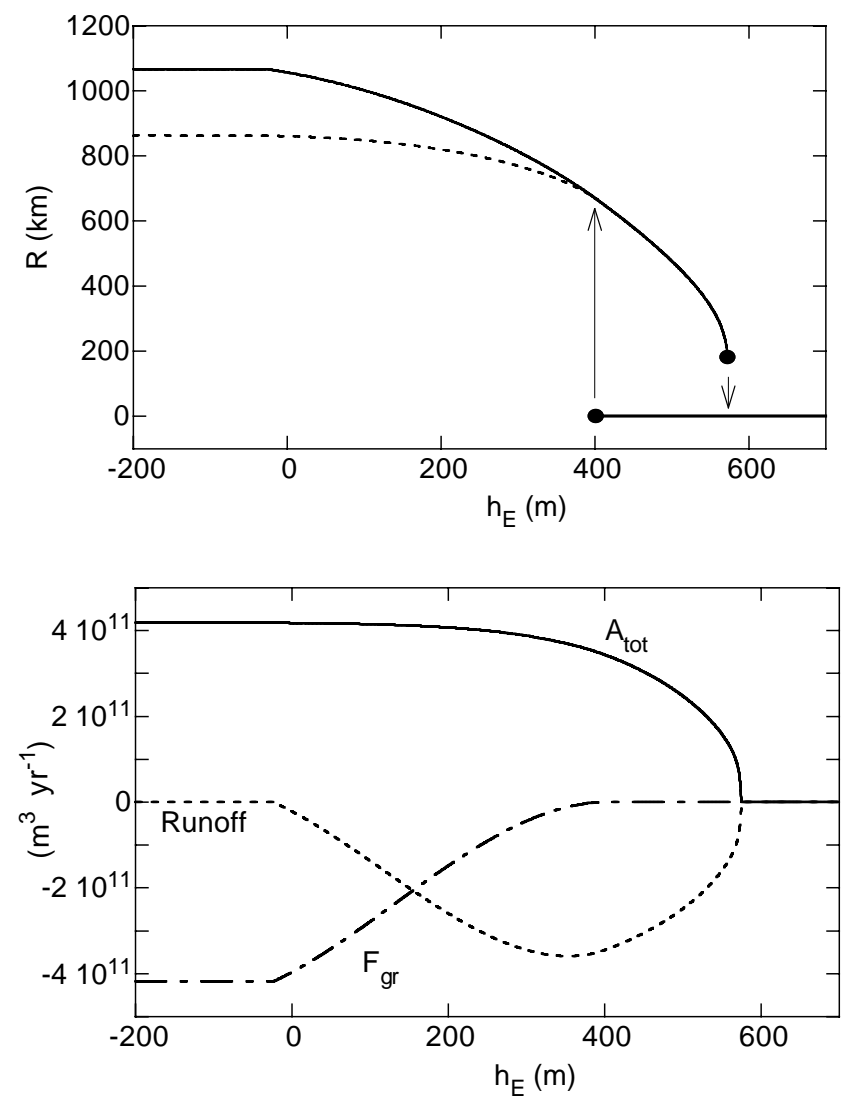

Fig. 5. Upper panel: stable equilibrium states of a marine icesheet. Parameter values: $d_{0}=400 \mathrm{~m}, s=0.0006, A=1 \mathrm{~m} / \mathrm{yr}$, $C_{R}=500 \mathrm{~km}, f=1 \mathrm{yr}^{-1}$ (solid line), $f=5 \mathrm{yr}^{-1}$ (dashed line). The lower panel shows the corresponding components of the mass budget (for $f=1$ ): total accumulation $\left(A_{t o t}\right)$, runoff, and flux across the grounding line $\left(F_{g r}\right)$. The coastline is at $r=667 \mathrm{~km}$.

\section{Time dependent behaviour}

The response time of the model ice-sheet depends on the size and the geometric setting, of course. For a given equilibrium state the response time, which is a volume time scale, can be determined by numerical experimentation or by a linear perturbation analysis (as was done in Oerlemans (2002) for the Antarctic ice-sheet model). We do not go into this analysis here, but look at the response to periodic forcing instead.

One possibility is to move the equilibrium line up and down periodically, as described by

$h_{E}(t)=h_{E, 0}-h_{E, A} \sin \left(\frac{2 \pi t}{P}\right)$

Here $h_{E, 0}$ is the reference value for the equilibrium-line altitude and $h_{E, A}$ the amplitude. In the following the period $P$ is set to $22000 \mathrm{yr}$ (Fig. 6a). The response of the model icesheet is obtained simply by numerical integration of Eq. (13).

Figure 6 shows the result for $h_{E, A}=300 \mathrm{~m}$ and different values of $h_{E, 0}$. Figure $6 \mathrm{~b}$ is for a continental ice-sheet with $s=0.001, A=1.0 \mathrm{mice} / \mathrm{yr}$ and $C_{R}=500 \mathrm{~km}$.
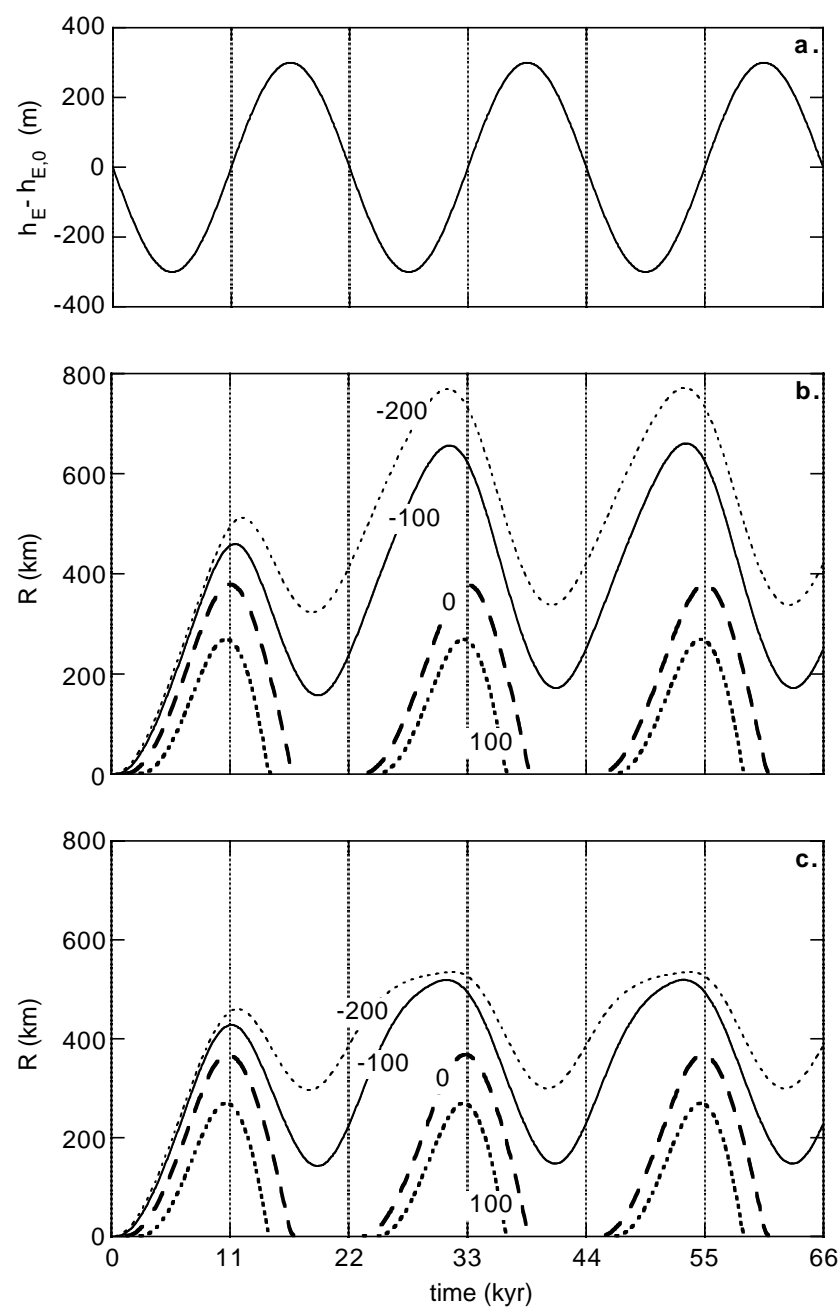

Fig. 6. Response of the ice-sheet radius $R$ to periodic variations in $h_{E}$, panel (a). In panel (b) the labels refer to $d_{0}-h_{E, 0}$ in (m), in panel (c) to $h_{E, 0}$ in (m).

The labels on the curves give $d_{0}-h_{E, 0}$, i.e. the reference equilibrium-line altitude with respect to the highest point of the undisturbed bed. As we can already anticipate from the structure of the equilibrium solutions (Fig. 4), there are two regimes: regime 1 in which the ice-sheet disappears completely and regime 2 in which the ice-sheet survives the maximum in $h_{E}$. This is in agreement with calculations that have been done with numerical ice-sheet models with somewhat different geometries (e.g. Oerlemans, 1982; Deblonde and Peltier, 1991). It can be seen that the time-lag between minimum equilibrium-line altitude and maximum ice-sheet size is larger for regime 1 . In fact, the time lag is close to $P / 4$.

The response of a marine ice-sheet to the periodic forcing is shown in Fig. 6c. For the continental ice-sheet discussed above, the solution could be presented in terms of $d_{0}-h_{E, 0}$. However, in the case of a marine ice-sheet we have to specify $d_{0}$, because it determines at which value of $R$ the ice-sheet edge moves into the sea. The results in Fig. $6 \mathrm{c}$ are for $s=$ 


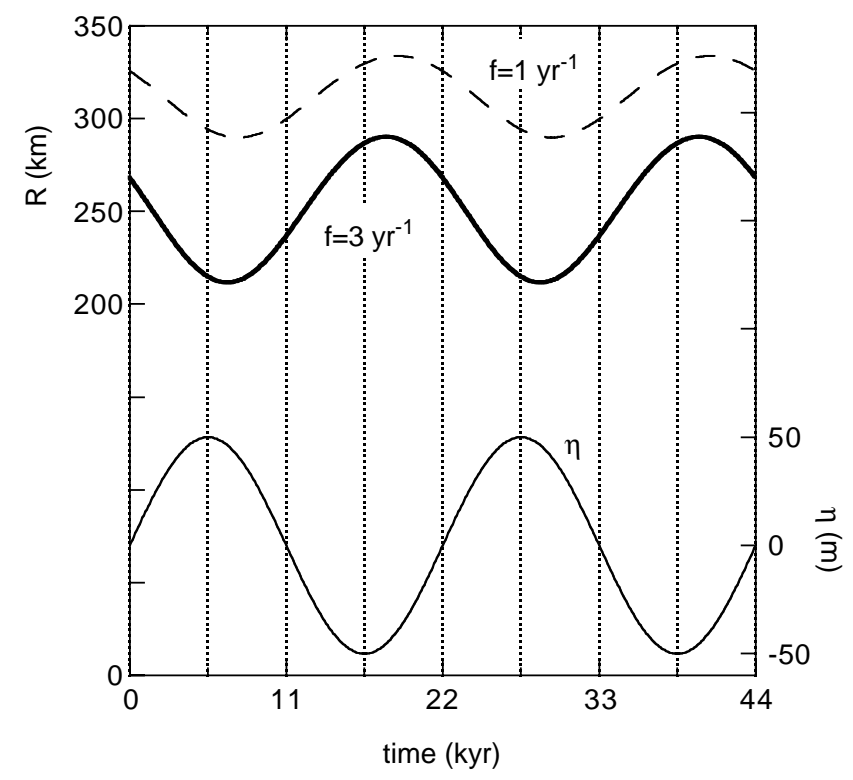

Fig. 7. Response of a marine ice sheet to periodic forcing of sea level $(\eta)$, for two values of the grounding-line flux parameter $f$. Model parameters: $s=0.001, d_{0}=150 \mathrm{~m}, h_{E}=150 \mathrm{~m}, A=$ $1 \mathrm{~m} / \mathrm{yr}, C_{R}=500 \mathrm{~km}$.

0.001 and $d_{0}=250 \mathrm{~m}$, which implies that the ice margin is in the sea for $R \geq 250 \mathrm{~km}$. For a good comparison, the scales of Fig. $6 \mathrm{~b}$ and $6 \mathrm{c}$ are the same. It is clear that the loss of ice by means of calving strongly reduces the response to changes in $h_{E}$.

One can also force the ice-sheet by changes in sea level. Figure 7 shows the response of a marine ice-sheet to periodic changes in sea level. The amplitude for $\eta$ was set to $50 \mathrm{~m}$, and the period again to $22 \mathrm{kyr}$. Because the effect is larger for icesheets with a larger proportion of the bed below sea level, a small value for the maximum bed elevation was chosen $\left(d_{0}=\right.$ $150 \mathrm{~m}$ ). The height of the equilibrium line was kept constant and equal to $d_{0}$. For $f=1 \mathrm{yr}^{-1}, R$ varies over a range of $65 \mathrm{~km}$. This range depends strongly on $f$, and therefore a curve for $f=3 \mathrm{yr}^{-1}$ is also shown. Apart from the stronger response to sea-level change, the mean radius of the ice-sheet is smaller now.

There is no consensus about the sensitivity of ice-sheets to sea-level change (Thomas and Bentley, 1978; Bentley, 1997; Hindmarsh and Le Meur, 2001), which makes it difficult to judge the results of the current simple model. In any way, the sensitivity and the characteristic response time depend very much on the specific geometry. In Fig. 8 an example is shown of a strong response to a linear rise in sea level of $100 \mathrm{~m}$ in $5000 \mathrm{yr}$. With $d_{0}=h_{E}=100 \mathrm{~m}$ and $s=0.001$, the equilibrium radius of the ice cap is about $225 \mathrm{~km}$. When sealevel starts to rise, the flux across the grounding line increases rapidly and reaches a peak after about 3000 years. The net mass budget reaches a minimum after about 4000 years. Then the size of the ice-sheet has decreased so much that all components of the mass budget become smaller. Note that
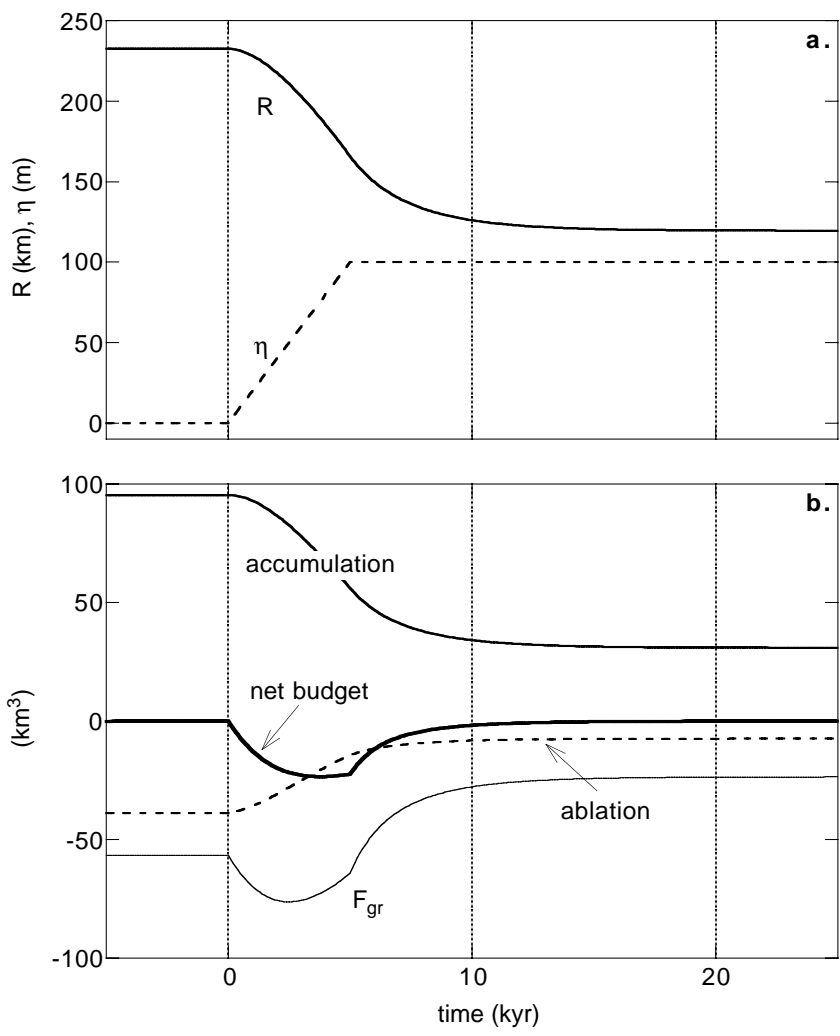

Fig. 8. Response of the model ice sheet to a linear change in sea level. Model parameters: $f=2 \mathrm{yr}^{-1}, s=0.001, d_{0}=50 \mathrm{~m}$, $h_{E}=50 \mathrm{~m}, A=1 \mathrm{~m} / \mathrm{yr}, C_{R}=500 \mathrm{~km}$. The upper panel (a) shows the ice-sheet radius $R$ and sea-level perturbation $\eta$. The lower panel (b) shows the components of the mass budget.

the relative change of the ablation is very large because part of the original ablation area is 'flooded' by the rising sea. It is probably unrealistic to keep the altitude of the equilibrium line fixed when sea-level rises, but this does not matter for the example discussed here.

\section{Coupling of ice-sheets}

It is widely accepted that during the Quaternary ice-sheets have played an important role in the evolution of the climate system. There is convincing geomorphological and geological evidence that at least five big ice-sheets have existed, namely the Laurentide ice-sheet, the Fennoscandian ice-sheet, the Kara/Barentsz Sea ice-sheet, the Greenland ice-sheet and the Antarctic ice-sheet. The Greenland and Antarctic ice-sheets are still there - the others are not. Each ice-sheet has its own history, affects the global climate, and therefore has an influence on the evolution of the other icesheets. Several mechanisms have been identified as being important in this respect. Sea-level fluctuations have been mentioned frequently as a process through which Northern Hemisphere ice-sheets have controlled partly the size of the Antarctic ice-sheet (Denton et al., 1986). Big ice-sheets have 

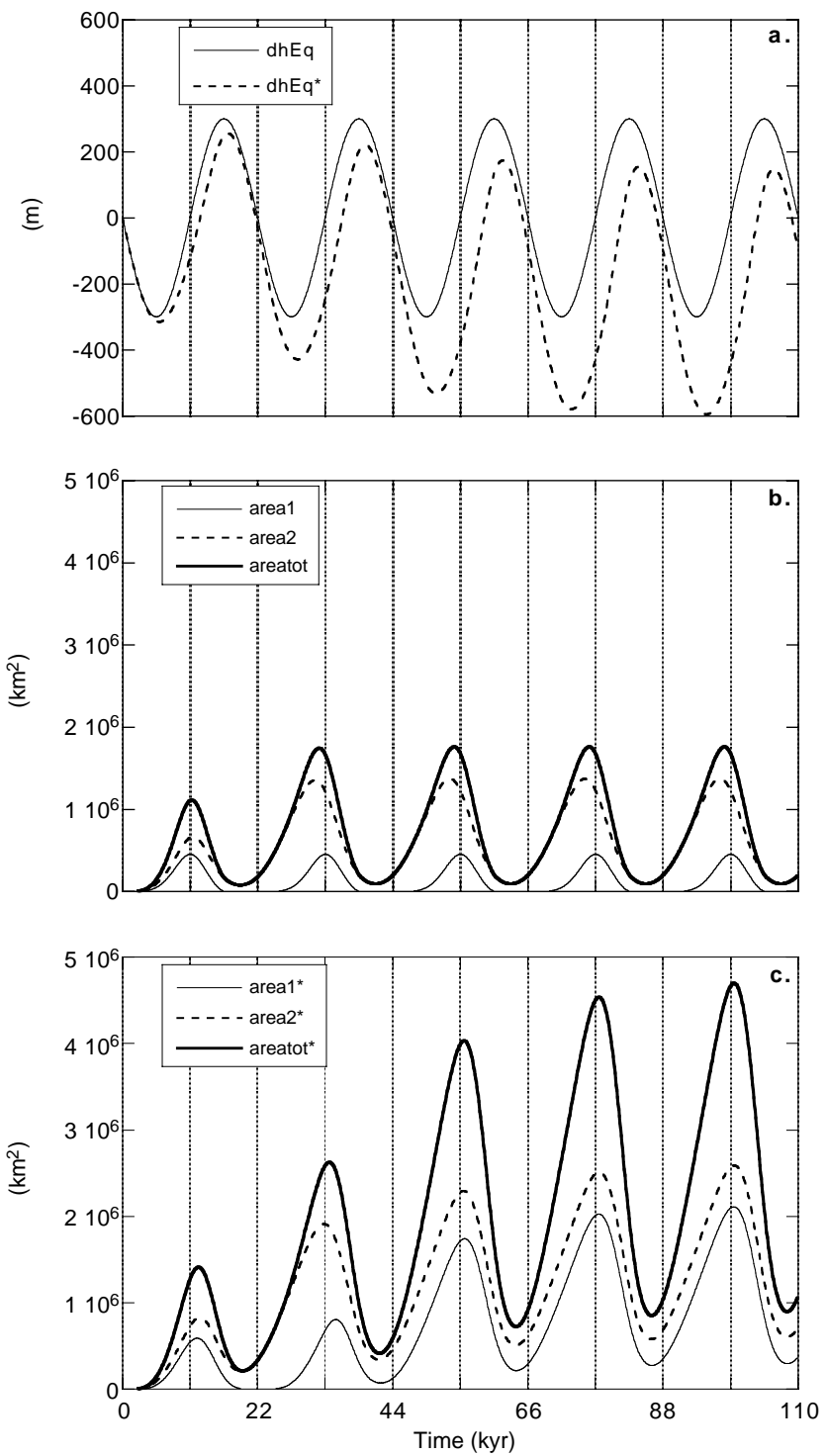

Fig. 9. Response of two coupled ice sheets to periodic forcing. Panel (a) shows the forcing (dhEq) and the resulting equilibriumline altitude when the ice-sheet feedback is included (dhEq*). Panel (b) shows the ice-sheet areas without coupling, and panel (c) with coupling.

a significant effect on the large-scale circulation patterns in the atmosphere, and notably on the distribution of precipitation. As many simulations of the climate of the Last Glacial Maximum have shown, the presence of ice-sheets contributes significantly to a cooler earth merely by increasing the surface albedo.

The ice-sheet model presented here can be used to study the interaction between ice-sheets. This requires a parameterisation of the climatic teleconnections, of course. It is beyond the scope of the present paper to elaborate on this, but two simple examples are shortly discussed.

In the first case we consider again the response to periodic forcing of the equilibrium-line altitude, but now for two ice-
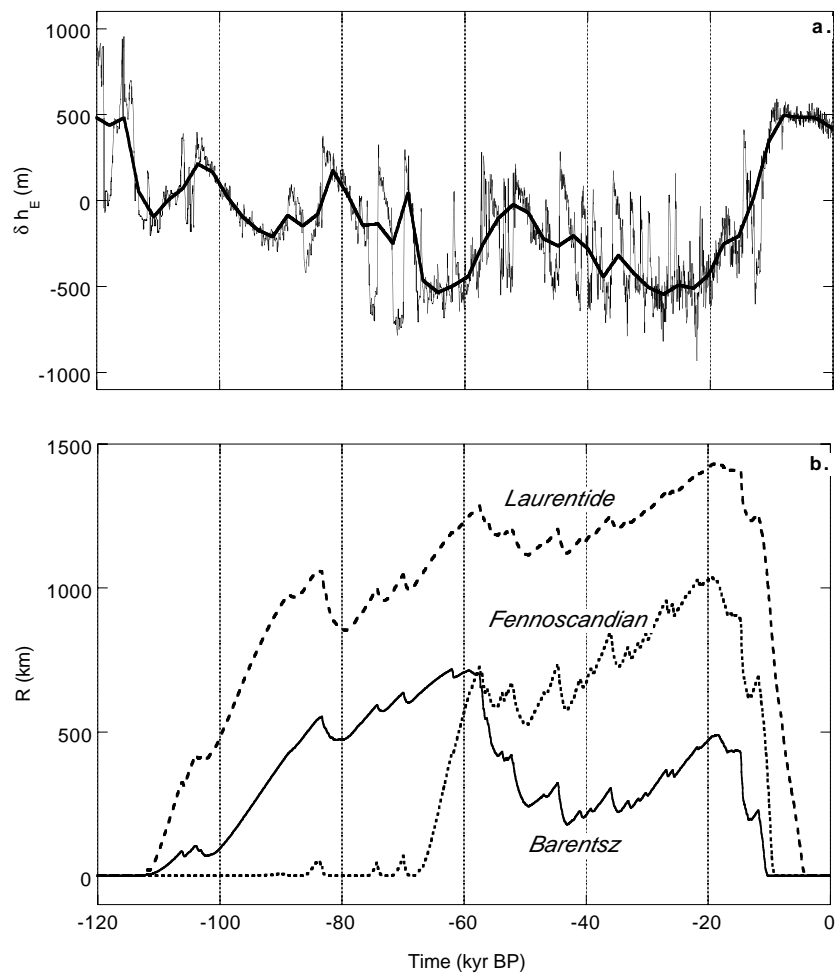

Fig. 10. Simulation of the three major Northern Hemisphere ice sheets through the last glacial cycle (b). Panel (a) shows the forcing of the equilibrium-line altitude, which follows the $\mathrm{d} 18 \mathrm{O}$ record from the GISP ice core. The solid line has been obtained by lowpass filtering.

sheets with slightly different geometry. The equilibrium-line altitude is prescribed as

$h_{E}(t)=h_{E, 0}-h_{E, A} \sin \left(\frac{2 \pi t}{P}\right)-h_{E, R}\left(\frac{R_{1}^{2}+R_{2}^{2}}{R_{E}^{2}}\right)$

As before, $h_{E, 0}$ is the reference value for the equilibriumline altitude and $h_{E, A}$ the amplitude of the periodic forcing ( $P$ is set to $22000 \mathrm{yr}$ again). The last term in Eq. (25) represents an additional drop in the equilibrium-line associated with the effect of the increasing or decreasing total icesheet area. With this formulation the growth of one ice-sheet favours the initiation and growth of the other one. For the case shown in Fig. 9, the only difference between the two icesheets is the value of $d_{0}$. For one ice-sheet the value of $d_{0}$ is $1250 \mathrm{~m}$, for the other ice-sheet $1350 \mathrm{~m}$. Other parameter values are: $h_{E, 0}=1250 \mathrm{~m}, h_{E, A}=300 \mathrm{~m}, R_{E}=10^{6} \mathrm{~m}$. These values imply that a full-grown ice-sheet with a $1000 \mathrm{~km}$ radius leads to a $200 \mathrm{~m}$ drop in the equilibrium line in the polar and subpolar regions of the Northern Hemisphere. The parameter values are just chosen to have the right order-ofmagnitude. There is no claim that they would actually match results from climate-modelling experiments.

The resulting ice-sheet areas as a function of time are shown in Fig. 9c. For comparison, the case with $h_{E, R}=$ 
Table 1. Model parameters used to simulate the Laurentide, Fennoscandian, and Barentsz ice-sheets through the last glacial cycle

\begin{tabular}{lcccc}
\hline & $d_{0}(\mathrm{~m})$ & $h_{E, 0}(\mathrm{~m})$ & $s$ & $A_{0}(\mathrm{~m} / \mathrm{yr})$ \\
\hline Laurentide ice-sheet & 1200 & 1000 & 0.0005 & 1.2 \\
Fennoscandian ice-sheet & 1200 & 1200 & 0.0007 & 1.5 \\
Barentsz ice-sheet & 300 & 100 & 0.0006 & 0.5 \\
\hline
\end{tabular}

0 (ice-sheets are not coupled) is shown in Fig. 9b. The equilibrium-line altitude for both cases is depicted in Fig. 9a. May be the most interesting aspect of the result is that it takes three cycles of forcing before the maximum total ice-sheet area is reached. In the terminology of the previous section, without the coupling one ice-sheet is in regime 1 and the other ice-sheet in regime 2 . With the coupling both ice-sheets end up in regime 2. Altogether, the coupling introduces a new (long) time scale in the system.

In the second case the oxygen isotope record of the GISP ice-core is taken as the driving force for an integration over the last 120000 years (Grootes et al., 1993). This is done by making the equilibrium-line altitude proportional to the $\delta^{18} \mathrm{O}$ value in such a way that the typical full glacial - interglacial contrast corresponds to a change in $h_{E}$ of about $1000 \mathrm{~m}$ (Fig. 10a). Three ice-sheets are simulated, representing the Laurentide, Scandinavian and the Barentsz ice-sheets (we use the term Barentsz ice-sheet for any ice in the Barentsz/Kara Seas region). The model parameters corresponding to these ice-sheets are given in Table 1. The values are not at all based on a sophisticated analysis of topographic data, but chosen in such a way that the Laurentide and Scandinavian ice-sheets are of a more 'continental' nature as compared to the Barentsz ice-sheet. The latter is a calving icesheet for most of the time.

As is clear from the analysis of the equilibrium states (Fig. 4), a smaller value of the bed slope s yields larger icesheets. Therefore the bed slope for the Laurentide ice-sheet has been given the smallest value, because it is generally accepted that in full glacial conditions this ice-sheet was the largest. It should be stressed, however, that here no attempt is made to optimize parameter values in a systematic way. The only purpose is to illustrate the possibilities of the icesheet model presented in this paper.

The $\delta^{18} \mathrm{O}$ record from the Greenland ice-sheet should be considered as a regional temperature proxy. Nevertheless, it is used here as a proxy for the variations in the equilibriumline altitude over the entire area where ice-sheets formed. The forcing is therefore formulated as

$h_{E}(t)=h_{E, 0}-150\left(\delta^{18} \mathrm{O}-\overline{\delta^{18} \mathrm{O}}\right)$,

where the $\delta^{18} \mathrm{O}$ value is measured in $\% o$ and $h_{E}(t)$ in $\mathrm{m}$. The overbar refers to the mean value over the last $120 \mathrm{kyr}$ (which is $-38.79 \%$ ).

Just to illustrate further how simple coupling mechanisms may operate, it is now assumed that a large Fennoscandian ice-sheet blocks the moisture supply for the Barentsz/Kara Sea region and also makes the climate here more continental with less clouds and higher temperatures in summer. This implies a rise of the equilibrium line. So for the Barentsz ice-sheet we write instead of Eq. (26):

$$
\begin{gathered}
h_{E}(t)=h_{E, 0}-150\left(\delta^{18} \mathrm{O}-\overline{\delta^{18} \mathrm{O}}\right) \\
+\lambda\left(1-\exp \left(-R_{S C} / C_{R}\right)\right)
\end{gathered}
$$

In this expression $R_{S C}$ is the radius of the Fennoscandian ice-sheet. So a larger value of $\lambda$ implies a larger rise of the equilibrium line. Here a value of $500 \mathrm{~m}$ is used, and $C_{R}=$ $500 \mathrm{~km}$. So for a Fennoscandian ice-sheet radius of $500 \mathrm{~km}$ the increase in $h_{E}$ is typically $300 \mathrm{~m}$.

The result is summarised in Fig. 10. The upper panel shows the forcing, i.e. the variations in the equilibrium-line altitude. The mean value of the forcing over the period of 120000 years is equal to zero. The ice-sheet radii are plotted in the lower panel.

First of all it can be noted that given its simplicity the model performs well. It is not difficult to chose the model parameters in such a way that the ice-sheets grow and decay in broad agreement with the paleo-record. The reference equilibrium-line altitude $\left(h_{E, 0}\right)$ for the Fennoscandian region has been set $200 \mathrm{~m}$ higher than for North America (Table 1). In this way the Fennoscandian ice-sheet 'misses' the temperature minima at 112 and $90 \mathrm{kyr} \mathrm{BP}$, but the ice-sheet grows rapidly from $67 \mathrm{kyr} \mathrm{BP}$ onwards. For the model parameters of Table 1, the Barentsz ice-sheet shows a similar development as the Laurentide ice-sheet, until the Fennoscandian ice-sheet starts growing and Eq. (26) becomes effective. The increase in the equilibrium-line altitude leads to a strong reduction of the size of the Barentsz ice-sheet. Following the warming at the end of the Quaternary, all the model icesheets start to decay. In spite of the short duration of the Younger Dryas, the signal in the GISP core is strong enough to make the model ice-sheets advance over a small distance (typically 20 to $50 \mathrm{~km}$ ). In this calculation the Fennoscandian ice-sheet has disappeared at $9 \mathrm{kyr} \mathrm{BP}$, whereas the Laurentide ice-sheet needs considerably more time to melt away.

Figure $10 \mathrm{~b}$ shows that with some tuning the present icesheet model is capable of reproducing the waxing and waning of the major Northern Hemisphere ice-sheets in response to a climate proxy for the last glacial cycle. This proves that the model is useful and is suited to study the effect of climatic teleconnections on ice-sheet dynamics. However, it should 
be stressed that this calculation does not provide an explanation for the glacial cycle and the occurrence of power in the long time scales - this is already contained in the forcing function!

\section{Discussion}

In this paper an ice-sheet model has been developed that can be used to study in a schematic way the interaction between ice-sheets and climate. The principle characteristic of the model is that it has no explicit spatial resolution. The radius is the only state variable, and for a given radius the ice-sheet profile and volume are always the same. However, compared to earlier analytical ice-sheet models, the formulation of the mass budget is more flexible and the ice-sheet can extend into the ocean.

In a zero-dimensional approach, the use of an axiallysymmetric configuration is probably more realistic than a geometry with full lateral symmetry (i.e. a north-south profile without ice discharge in the east-west direction). However, there is a price to pay: the equilibrium-line altitude is the same around the periphery of the ice-sheet, which differs from the classical picture for the Northern Hemisphere in which the equilibrium line slopes upwards in southerly direction. It is not so clear how serious this is, however. Looking at the Greenland ice-sheet, the equilibrium-line varies considerably, but not consistently in a north-south direction. Due to strongly decreasing accumulation rates when going northwards, the lowering of the equilibrium-line altitude is suppressed considerably. Therefore, an approach in which an ice-sheet extends from high ground in all directions is perhaps not further from reality than an ice-sheet that starts at the margin of the polar ocean and grows southward (this is certainly wrong for Scandinavia). Even in North America there is a lot of evidence that in many phases the ice-sheet was huge in the south with some island in the north almost ice-free.

The model can be developed further within the framework presented in this paper. An ice-sheet can be split into sectors with different parameters to make the geometry and the representation of the climatic setting more realistic. It is also possible to account for the delay in the bed response by introducing a separate prognostic equation for the elevation of the bed. Along another line, 'surge-type' behaviour can be generated by including a prognostic equation for the profile parameter $\mu$ and impose rapid changes in $\mu$ (independently or related to the properties of the model ice-sheet or the forcing).

The approach presented in this paper cannot replace the calculations with sophisticated numerical models. Nevertheless, it is instructive to investigate simpler models, because it allows a more thorough study of the parameter space. The simplicity and computational efficiency of the ice-sheet model presented here makes it very suitable for coupling with low-order climate models.

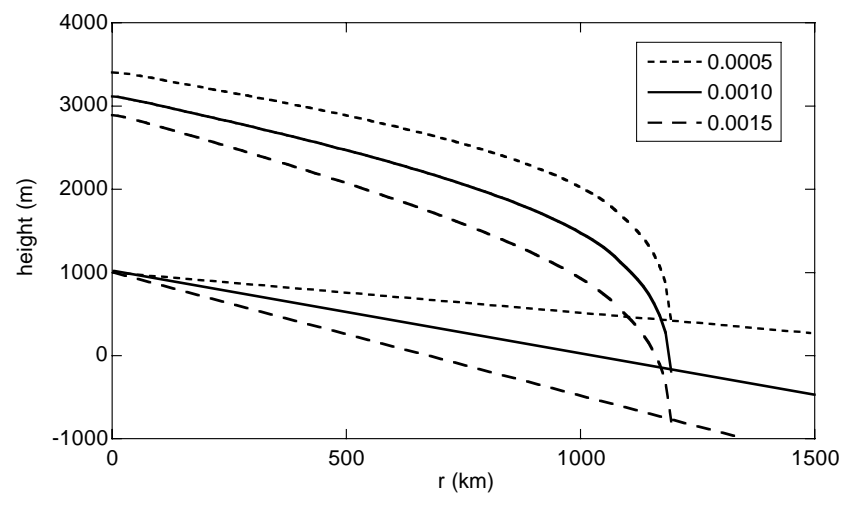

Fig. A1. Three steady-state ice-sheet profiles calculated with a numerical plane-shear model for three values of the (undisturbed) bed slope (labels).

\section{Appendix A}

The difference between perfectly plastic and plane-shear icesheet models have been discussed in some detail by Van der Veen (1999). The comparison he shows is for ice-sheets on a bed that is originally horizontal.

First of all the perfectly plastic solution (parabola) has a finite slope at the centre, whereas the plane-shear model has a zero slope. A zero slope is clearly more realistic. However, the shape of the central part of the ice-sheet is of little significance in the context of the present paper, because it does not affect the total mass budget (the accumulation rate is constant above the runoff line).

Then the plane-shear solution predicts a higher ice-sheet close to the ice-sheet edge. This does have an implication for the mass budget, because the intersection of the runoff line with the ice-sheet surface will be further away from the ice edge. Therefore, for a given mean surface elevation and radius, the plane-shear ice-sheet will have a somewhat larger mass budget than the corresponding perfectly plastic ice-sheet. Nevertheless, it is questionable if the planeshear solution with its steeper edge is a more realistic model. Basel melting and enhanced sliding, the presence of soft deformable sediment layers, and the formation of ice streams altogether make that the plane-shear model predicts an icesheet edge that is too steep, in particular in the case of an icesheet that extends into the sea. In this respect the perfectlyplastic model seems to do a better job, albeit for the wrong reason.

The considerations given above also apply to ice-sheets on a bed with a small slope. Equilibrium ice-sheet profiles for plane-shearing flow were calculated for a number of bed slopes (Fig. A1). The model equations and numerical procedure to obtain the solution are not given here, because it can be found in a number of textbooks (e.g. Van der Veen, 1999). For each value of the bed slope the height of the runoff line was adjusted in such a way that the same equilibrium radius was found. A comparison between Fig. A1 
and Fig. 1a reveals the differences that have been discussed above. Nevertheless, given the other simplifications used in the model developed in this paper, the differences are acceptable. We thus conclude that the parameterisation of the effect of the bed slope as given by Eq. (4) is adequate. It should be noted, however, that the values of $\mu_{0}$ and $c$ used in this paper only apply to cases with sufficiently small bed slopes. When the model is applied to steeper beds, further numerical experimentation is needed to optimise the values of these parameters.

Acknowledgements. I thank the Ice-and-Climate group at the Institute for Marine and Atmospheric Research, Utrecht University, for useful discussions on an earlier draft of this paper. An anonymous reviewer and D. Pollard are thanked for their many helpful comments.

\section{References}

Bentley, C. R.: Rapid sea-level rise soon from West Antarctic icesheet collapse?, Science, 275, 1077-1078, 1997.

Bintanja, R., Van de Wal, R. S. W., and Oerlemans, J.: Global ice volume variations through the last glacial cycle simulated by a 3-D ice-dynamical model, Quaternary Int., 95/96, 11-23, 2002.

Deblonde, G. and Peltier, W. R.: A one-dimensional model of continental ice volume fluctuations through the Pleistocene: implications for the origin of the Mid-Pleistocene climate transition, J. Climate, 4, 318-344, 1991.

Denton, G. H., Hughes, T. J., and Karlén, W.: Global ice-sheet system interlocked by sea level, Quat. Res., 26, 3-26, 1986.

Grootes, P. M., Stuiver, M., White, J. W. C., Johnsen, S. J., and Jouzel, J.: Comparison of oxygen isotope records from the GISP2 and GRIP Greenland ice cores, Nature, 366, 552-554, 1993.

Haakensen, N. (Ed): Glasiologiske Undersøgelser i Norge 1992 og 1993, Norges Vassdrags-og Energiverk, Oslo, 1995.

Haeberli, W., Hoelzle, M., Suter, S., and Frauenfelder, R.: Fluctuations of Glaciers, 1990-1995, (Vol. VII) IASH (ICSI)-UNEPUNESCO, 1998.

Hindmarsh, R. C. A. and Le Meur, E.: Dynamical processes involved in the retreat of marine ice-sheets, J. Glaciol., 47 (157), 271-282, 2001.
Marsiat, I.: Simulation of the Northern Hemisphere continental icesheets over the last glacial-interglacial cycle: experiments with a latitude-longitude vertically integrated ice-sheet model coupled to a zonally averaged climate model, Paleoclimates, 1, 59-98, 1994.

Milne, G. A., Mitrovica, J. X., and Schrag, D. P.: Estimating past continental ice volume from sea-level data, Quaternary Sci. Rev., 21, 361-376, 2002.

Oerlemans, J.: Model experiments on the $100000 \mathrm{yr}$ glacial cycle, Nature, 287, 430-432, 1980.

Oerlemans, J.: Some basic experiments with a vertically-integrated ice-sheet model, Tellus, 33, 1-11, 1981.

Oerlemans, J.: Glacial cycles and ice-sheet modelling, Clim. Change, 4, 353-374, 1982.

Oerlemans, J.: Global dynamics of the Antarctic ice-sheet, Clim. Dyn., 19, 85-93, 2002.

Oerlemans, J. and Van der Veen, C. J.: Ice Sheets and Climate, Reidel, 1984.

Pollard, D.: A simple ice-sheet model yields realistic $100 \mathrm{kyr}$ glacial cycles, Nature, 296, 334-338, 1982.

Tarasov, L. and Peltier, W. R.: A high-resolution model of the $100 \mathrm{ka}$ ice-age cycle, Ann. Glaciol., 25, 58-65, 1997.

Thom, R.: Structural stability and morphogenesis, Benjamin (Reading, Mass.), 1975.

Thomas, R. H. and Bentley, C. R.: A model for holocene retreat of the West Antarctic Ice Sheet, Quat. Res., 10, 150-170, 1978.

Tushingham, A. M. and Peltier, W. R.: Ice-3G: A new global model of late Pleistocene deglaciation based upon geophysical predictions of post-glacial relative sea level change, J. Geophys. Res., 96 (B3), 4497-4523, 1991.

Van de Wal, R. S. W. and Oerlemans, J.: An energy balance model for the Greenland ice-sheet, Glob. Plan. Change, 9, 115-131, 1994.

Van der Veen, C. J.: Fundamentals of Glacier Dynamics, Balkema, Rotterdam, 1999.

Vialov, S. S.: Regularities of glacial shields movement and the theory of plastic viscous flow, Int. Ass. Hydrol. Sci. Publ., 47, 266275, 1958.

Weertman, J.: Stability of ice-age ice-sheets, J. Geophys. Res., 66, 3783-3792, 1961.

Weertman, J.: Milankovitch solar radiation variations and ice age ice-sheet sizes, Nature, 261, 17-20, 1976. 